International Journal of Pure and Applied Mathematics

Volume 85 No. 1 2013, 129-140

ISSN: 1311-8080 (printed version); ISSN: 1314-3395 (on-line version)

url: http://www.ijpam.eu

doi: http://dx.doi.org/10.12732/ijpam.v85i1.10

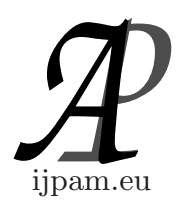

\title{
SINGULARITIES OF A THEMPERATURE FIELD IN A ROAD CONSTRUCTION WITH AN UNDERGROUND HEAT PIPELINE
}

\author{
K. Aitbaev ${ }^{1}$ §, S.N. Duysebaev², A.A. Kanibekova ${ }^{3}$ \\ $1,2,3$ Department of Mathematics \\ International Kazakh-Turkish \\ University named after A. Yasawi \\ Turkestan, 161200, REPUBLIC OF KAZAKHSTAN
}

\begin{abstract}
Results of experimental and theoretical researches of a temperature field in a ground around an underground heat pipeline laid under the urban road construction are given. The differential equation of a stationary thermal conductivity for an inhomogeneous multiply connected domain is solved by the finite element method. Results of a natural experiment are used for constructing the mathematical model.
\end{abstract}

AMS Subject Classification: 86-05, 86-08, 81T80, 80M10

Key Words: heat pipeline, temperature field, road construction, finite element method, natural experiment, and underground collector

\section{Introduction}

The presence of a heat pipeline in the ground foundation of urban roads modifies

Received: January 23, 2013

(C) 2013 Academic Publications, Ltd.

${ }^{\S}$ Correspondence author url: www.acadpubl.eu 
significantly the usual water-heating mode of road constructions [1]. In particular, stress-strain state of the whole road structure depends on the ground humidity of foundation. Therefore studying and detecting singularities of hydrothermal regime of road constructions with an underground heat pipeline is very important question for modern road science and practice [2].

Underground heat pipelines are laid in a channel or with the help of channelfree way [3]. In a series of works [4-6], on the basis of theoretical and experimental researches, it has been developed and was tested a model that allows to determine the temperature in the soil subgrade of the road at the intersection of the latter with an underground heat supply track. In the works, it was considered the model of thermal calculating the system "pavement road bed" proposed by V.M. Sidenko, and also complete analysis of the wellknown method for calculating the temperature change of the ground around a 2-channel-free tube heat pipeline, developed by E.P. Shubin, was carried out. Authors succeeded in obtaining an analytical expression to determine the temperature at any point of the soil mass of subgrade and pavement situated above the channel-free two-pipe heat pipeline.

In the present work, it is considered interaction of an underground heat pipeline laid under the roadway with a multilayer pavement. Here results of natural experimental researches are also given, which have been used in constructing the mathematical model of the formation process of a temperature field around an underground heat pipeline.

\section{Formulation of a Natural Experiment}

A natural experiment was carried out in Almaty city in the period from October 2001 to February 2003. The purpose of this experiment was to determine change patterns of the true temperature field in the ground around an underground heat pipeline. Some results of the experiment were published in [7].

For a natural experimental study of the temperature regime of urban road constructions, a road section was selected under which an underground heating main has been laid (Fig. 1). Thermoelectric sensors [8] have been established across the cross section of the experimental section on a specially designed scheme (Fig. 1).

The following notations are used on Figure 1: I is double-layer asphalt concrete; II is a layer of sandy gravel; III is light loam, IV is crushed stone from firm breeds; $a_{1}=3.85 \mathrm{~m}$ is the distance from the boundary of the trench opening to a curb; $a_{2}=0.90 \mathrm{~m}$ is the distance from the boundary of the trench 


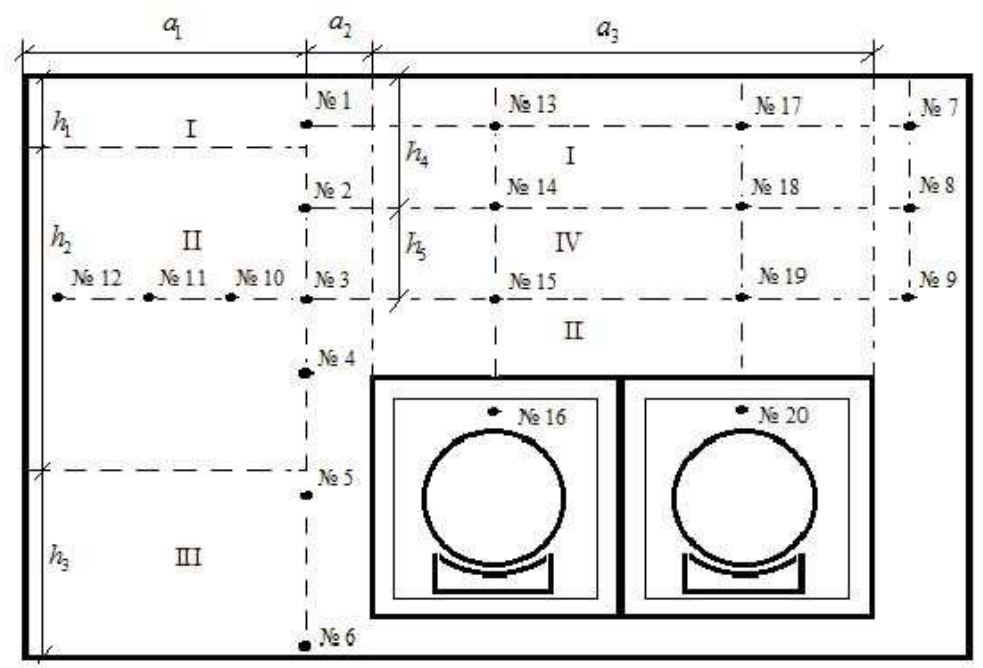

Figure 1: The principal scheme of arrangement of the road structure elements and thermal sensors on the experimental section

opening to a collector; $a_{3}=2.90 \mathrm{~m}$ is the total width of a double collector; $h_{1}=0.34 \mathrm{~m}$ is the thickness of the asphalt concrete to repair; $h_{2}=0.70 \mathrm{~m}$ is the thickness of the layer of sandy gravel; $h_{3}=1.16 \mathrm{~m}$ is the thickness of the ground of natural occurrence, consisting of light loam; $h_{4}=0.20 \mathrm{~m}$ is the thickness of double-layer asphalt concrete laid on completion of repair heating main; $h_{5}=0.30 \mathrm{~m}$ is the thickness of crushed stone; No.1 - No.20 are numbers of thermoelectric sensors.

\section{Results of the Natural Experiment}

On Figures 2-3, graphs of the temperature changes in horizontal and vertical cross-sections of the studied domain are given that have been constructed by indications of thermal sensors.

Character of changes of the temperature field in the fall according to indications of a horizontal row of sensors is shown on Figure 2. Here we use the readings taken from sensors No.12, No.11, No.10, No.3, No.15, No.19 and No.9 at an outdoor temperature $T_{V}=+15^{\circ} \mathrm{C}$. Sensors were laid at a depth of 50 cm (graph I, Fig. 2).

Peak temperature values fall on the level of the heat pipeline. And their 


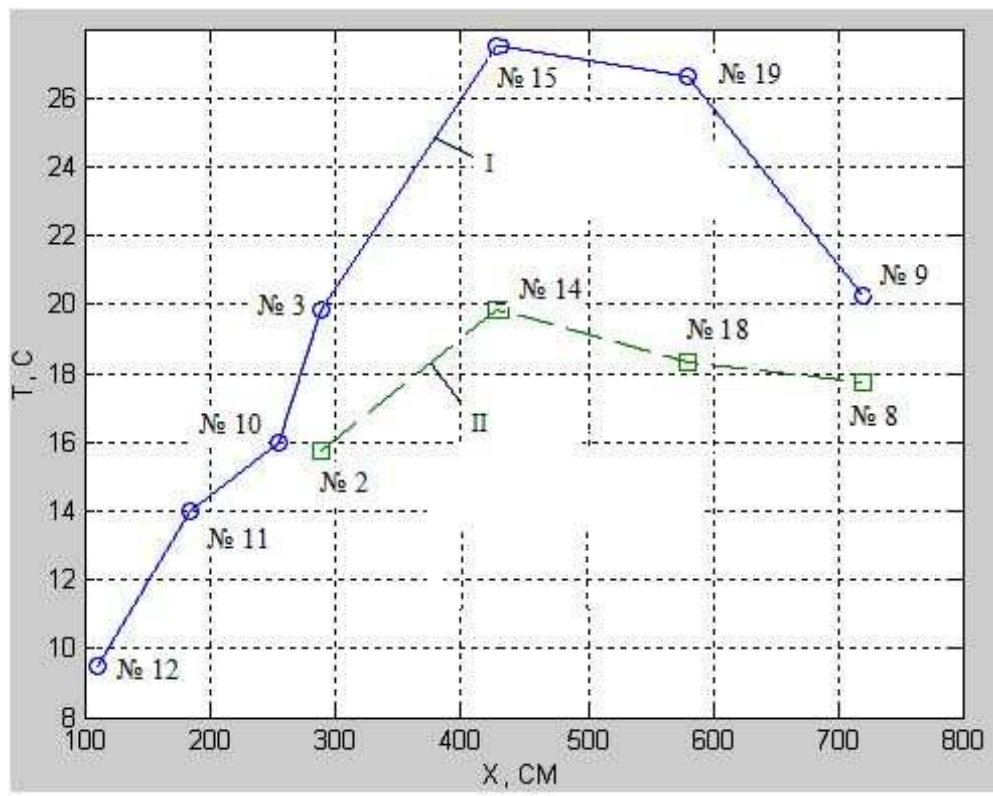

Figure 2: Experimental data at the temperature $T_{V}=+15^{\circ} \mathrm{C}$

maximum value is observed over the pipe of hot water. On the same Figure, there is a comparing graph built by indications of another horizontal row of sensors No.2, No.14, No.18 and No.8 located at a depth of $20 \mathrm{~cm}$ (graph II, Fig. $2)$.

The determining role of a heat pipeline in the formation of the temperature field in the investigated domain follows from comparison of two graphs. To study the patterns of formatting the temperature field in depth, vertical rows of sensors were placed in such a way as to cover more complete the influence area of heat pipelines. The first vertical row of sensors No.2, No.3, No.4, No.5, No.6 starts with the base of an asphalt concrete layer, is at a distance of $80 \mathrm{~cm}$ from the left side of reinforced concrete collectors and reaches a depth of 2.2 meters, which is below the level of the last ones (Fig. 1). The next two rows of sensors, namely, the second (sensors No.14 and No.15) and third (sensors No.8 and No.9) vertical rows are arranged along the vertical axis of concrete collectors, and they had to identify singularities of formation of the temperature field near the zone of influence of a heat supply pipe and a tube of feeding back.

Figure 3 shows a graph comparing the readings of all three vertical rows of sensors, taken at an outdoor temperature $T_{V}=+17^{\circ} \mathrm{C}$. Graph I, correspond- 


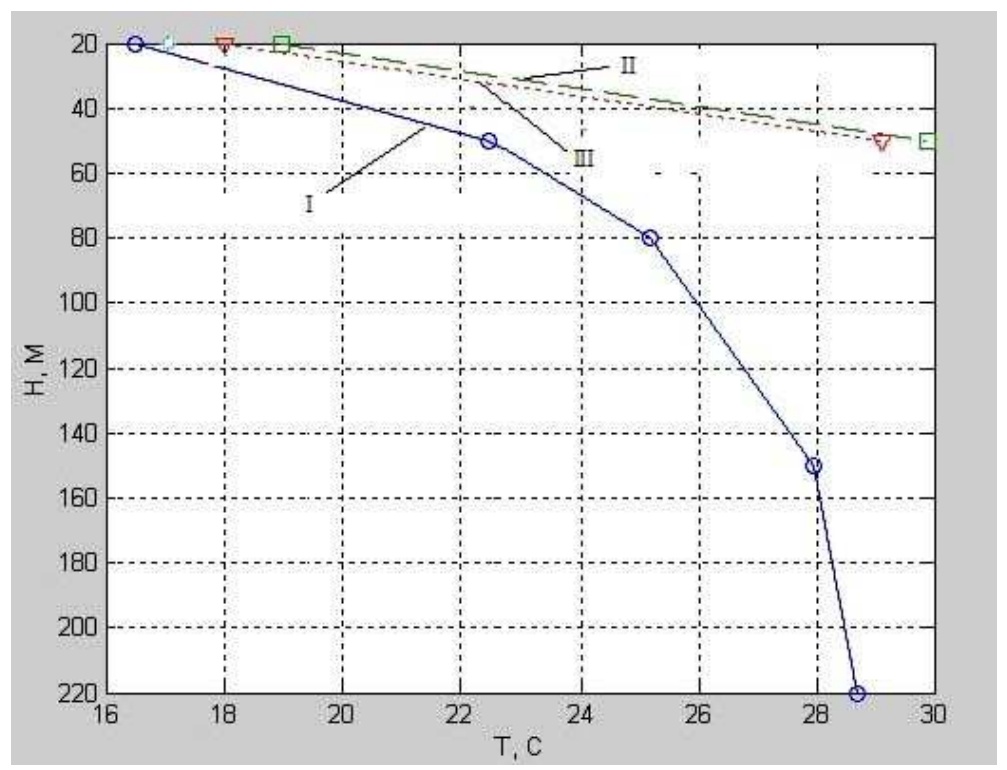

Figure 3: Indications of a vertical row of sensors at the temperature $T_{V}=+17^{\circ} \mathrm{C}$

ing to readings of sensors No.2, No.3, No.4, No.5 and No.6, shows that high temperature persists until the late summer in the neighborhood of an underground heat pipeline. Proximity of curves II and III corresponding to sensor readings in the second and third vertical rows shows that, prior to the heating season, temperature values of water in the pipes of forward and reverse flow are close.

For mathematical modelling the temperature field of a road construction with an underground heat pipeline, its following specialties are taking into account, which have been established with the help of a natural experiment:

- positive temperature remains in the neighborhood of an underground heat pipeline throughout the year;

- in a cold period, the upper boundary of the zone with positive temperature is limited to the lower surface of the asphalt layers;

- horizontal boundaries of the zone with positive temperature extend beyond the borders collector by more than $1 \mathrm{~m}$. 


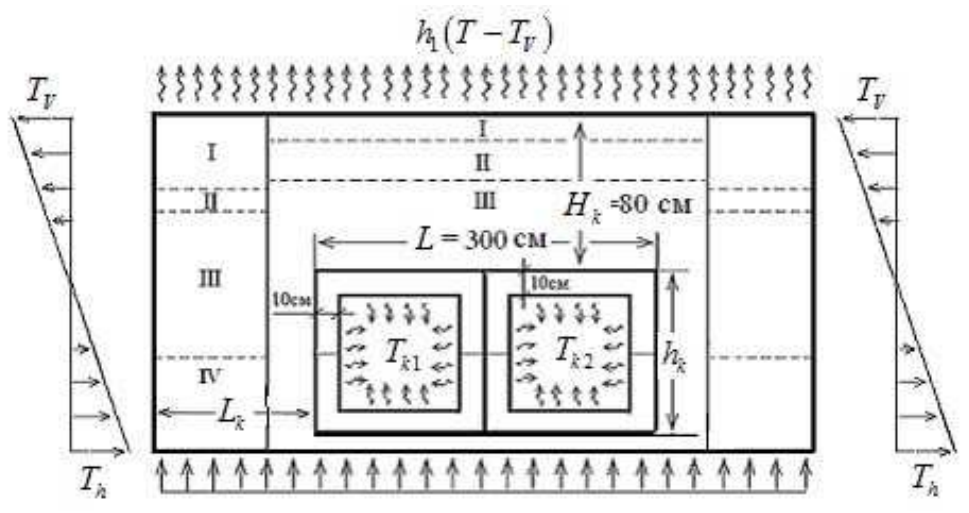

Figure 4: The design scheme of the mathematical model

\section{Constructing the Mathematical Model}

For the theoretical research of the temperature field in a road construction with a heat pipeline, a mathematical model of the process was constructed, where the results of a natural experiment were used to assign boundary conditions (Fig. 4). All the linear dimensions of the design scheme correspond to analogous parameters of the experimental section (Fig. 1).

The following conditional notations are adopted in Figure 4: I is a doublelayer asphalt concrete; II is rubble from firm breeds; III is gravel-sand mixture; IV is ground of natural occurrence, light loam; $T_{V}$ is the outdoor temperature; $T_{h}$ is the ground temperature at a depth of $h$ meters; $T_{k 1}$ and $T_{k 2}$ are the air temperatures inside the collectors; $h_{k}=1.40 \mathrm{~m}$ is the height of reinforced concrete collector; $\mathrm{L}$ is the total width of collectors; $L_{k}$ is the distance from the collector boundary to the boundary of the design scheme.

In the mathematical model of the road structure with an underground heat pipeline, temperature of the outside air is taken into account through the convective heat transfer of air and road pavement surface by the law $h_{1}\left(T-T_{V}\right)$, here $h_{1}$ is the convective heat exchange coefficient of outside air with the surface of asphalt (Fig. 4).

The boundary conditions at the lower boundary of the investigated region are established on the assumption that the soil temperature will be constant in a certain, fixed depth $h$ throughout the year, and will be equal to $T_{h}[7]$.

The temperature of the medium on the sides of design scheme can be considered as a linear variable - from the outside air temperature $T_{V}$ to the ground 
temperature $T_{h}$ at a depth of $h$. The horizontal boundary of the design scheme will be assigned to the vertical section where the gradient of the temperature field will be sufficiently low enough that it will be established with the help of a numerical experiment.

Conditions on interior surfaces of collectors will be determined by means of solving a semi-inverse problem. In setting up the natural experiment in ferroconcrete collectors thermal sensors (No.16 and No.20, Fig. 1) were installed, which broke down at the beginning of the experiment. However, even the availability of experimental data on the temperature inside the collectors, cannot fully solve the problem of choice of boundary conditions in the mathematical model of heat transfer process in the considered road construction. Experimental data will cover a limited range of change of outdoor temperature $T_{V}$ corresponding to the true temperature change inside collectors during the natural experiment, and they can only be used for tests of the mathematical model.

The differential equation of stationary thermal conductivity for an inhomogeneous multiply connected domain was solved by the method of finite elements $[9,10]$. To assign boundary conditions inside the collectors, first functional relationship between the outdoor temperature and the temperature of the water in the tubes of a heat conductor are installed. The water temperature in the pipes forward and reverse underground heat conductor is directly dependent on the ambient temperature, which is analytically described [7] by the following piece-wise linear function of temperature in the pipes forward $\left(T_{p r}\right)$ and reverse flow $\left(T_{o b r}\right)$ outside air temperature $\left(T_{V}\right)$ :

$$
\begin{aligned}
& T_{p r}=\left\{\begin{array}{l}
60^{\circ} \mathrm{C}, \text { if } T_{V} \geq 4.1^{\circ} \mathrm{C}, \\
-2.5 \cdot T_{V}, \text { if } 4.1^{\circ} \mathrm{C}>T_{V} \geq-19.1^{\circ} \mathrm{C}, \\
118^{\circ} \mathrm{C}, \text { if } T_{V}<-19.1^{\circ} \mathrm{C} .
\end{array}\right. \\
& T_{o b r}=\left\{\begin{array}{l}
0.51 \cdot T_{V}+37.9^{\circ} \mathrm{C}, \text { if } T_{V} \geq 4.1^{\circ} \mathrm{C}, \\
-1.06 \cdot T_{V}+44.9^{\circ} \mathrm{C}, \text { if } 4.1^{\circ} \mathrm{C}>T_{V} \geq-19.1^{\circ} \mathrm{C}, \\
0.51 \cdot T_{V}+74.21^{\circ} \mathrm{C}, \text { if } T_{V}<-19.1^{\circ} \mathrm{C} .
\end{array}\right.
\end{aligned}
$$

Similar functional relationships need to build between the outdoor temperature $T_{V}$ and the air temperature inside the collector $T_{k 1}$ and $T_{k 2}$, respectively. To do this, one needs a series of experimental calculations that uses experimental data.

To determine values of temperature inside collectors $T_{k 1}$ and $T_{k 2}$, first the graph of experimental data is constructed. The temperature is then calculated on the mathematical model in the section where they were placed thermoelectric sensors No.3, No.4, No.5, No.6 for a priori selected $T_{k 1}$ and $T_{k 2}$. Moreover, 


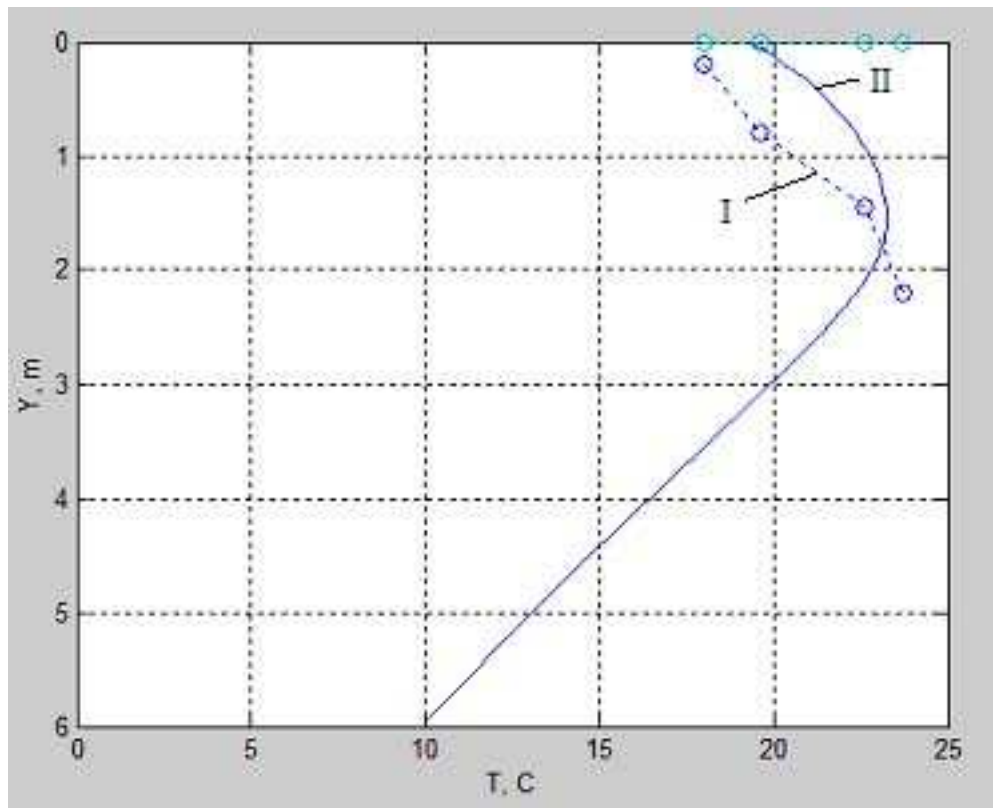

Figure 5: Graphs of comparison of the experimental and calculated data for the vertical row of sensors

one needs to keep in mind that first the temperature value $T_{k 1}$ is chosen while choosing $T_{k 1}$ and $T_{k 2}$. Because the temperature in the considered vertical section is mainly determined by the value of $T_{k 1}$ since the collector of the feedforward tube is in close proximity to this section. And the temperature value in the second collector $T_{k 2}$ can be selected taking into account the relations between the values $T_{p r}$ and $T_{o b r}$ by relation (1).

Thus, the missing boundary conditions in the form of air temperature in the collectors $T_{k 1}$ and $T_{k 2}$ first are assigned a priori, and they will change as long until there will be sufficient proximity of the experimental and theoretical curves in the temperature development curves in the considered cross-section.

For experimental data corresponding the outdoor temperature $T_{V}=+19^{\circ} \mathrm{C}$ , this proximity occurs at the values of air temperature inside the collector, equal $T_{k 1}=29^{\circ} \mathrm{C}$ and $T_{k 2}=27^{\circ} \mathrm{C}$, respectively. Graphs of comparison of the experimental and calculated data for the vertical row of sensors No.3-No.6 are given on Figure 5. Graphs of comparison for the horizontal row of sensors No.3, No.15, No.19 and No.9 taken also at the outdoor temperature $T_{V}=+19^{\circ} \mathrm{C}$ and calculated data at temperatures $T_{k 1}=29^{\circ} \mathrm{C}, T_{k 2}=27^{\circ} \mathrm{C}$, and $T_{h}=10^{\circ} \mathrm{C}$ are 


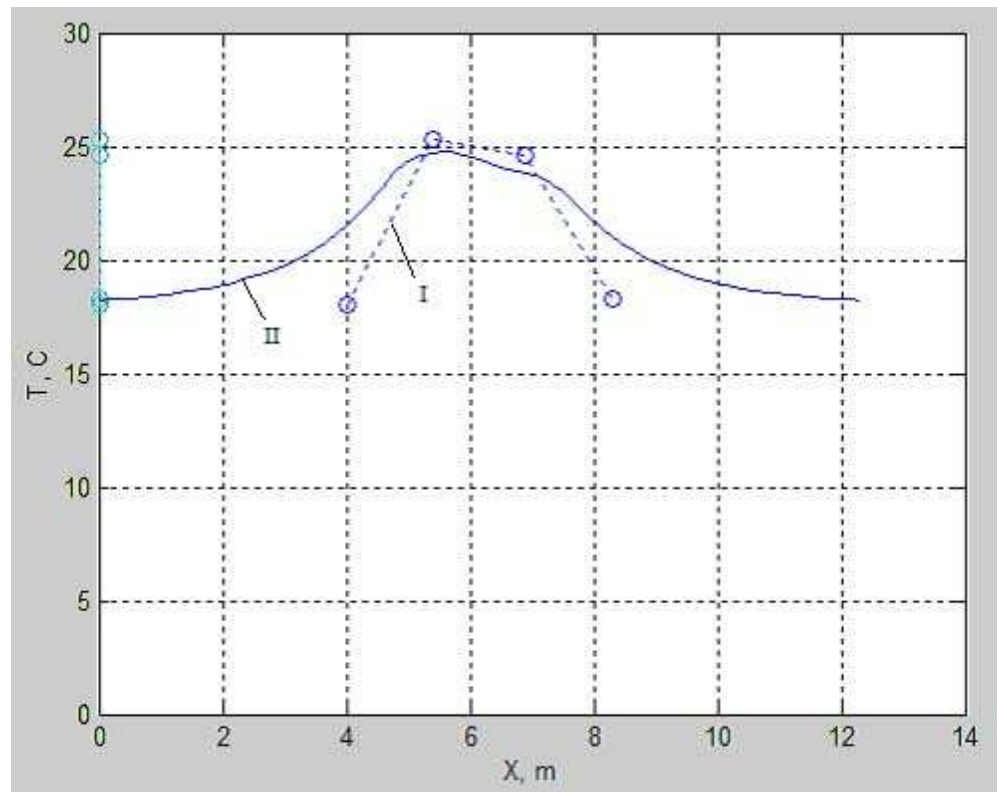

Figure 6: Graphs of comparison of the experimental and calculated data for the horizontal row of sensors

given in Figure 6.In the graphs 5 and 6 through I, II denote the experimental and calculated curves, respectively.

Similar calculations for the range outdoor temperature from $-30^{\circ} \mathrm{C}$ to $+30^{\circ} \mathrm{C}$ allowed to establish the functional relationship between the outdoor temperature $T_{V}$ and the air temperature inside the collector $T_{k 1}$ and $T_{k 2}$ in the form of the following piece-wise linear functions:

$$
\begin{aligned}
& T_{k 1}=\left\{\begin{array}{l}
-0.93 \cdot T_{V}+48.51^{\circ} \mathrm{C}, \text { if } 4.1^{\circ} \mathrm{C}>T_{V} \geq-19.1^{\circ} \mathrm{C}, \\
66.28^{\circ} \mathrm{C}, \text { if } T_{V}<-19.1^{\circ} \mathrm{C} .
\end{array}\right. \\
& T_{k 2}=\left\{\begin{array}{c}
-0.69 \cdot T_{V}+30.69^{\circ} \mathrm{C}, \text { if } 4.1^{\circ} \mathrm{C}>T_{V} \geq-19.1^{\circ} \mathrm{C}, \\
0.51 \cdot T_{V}+53.61^{\circ} \mathrm{C}, \text { if } T_{V}<-19.1^{\circ} \mathrm{C} .
\end{array}\right.
\end{aligned}
$$

\section{Results of Theoretical Researches}

Research of the temperature field in the road construction on the mathematical model (Fig. 4) begins with the appointment of the following numeric values for the input data. At a depth of $h=5.95 \mathrm{~m}$ temperature in the ground is 
considered to be constant throughout the year and equal $T_{h}=10^{\circ} \mathrm{C}$. On each side of the design scheme the temperature changes by a linear law from $T_{h}$ up to the temperature of the ambient air. Convective heat transfer with the outside air takes place on surface of the pavement. The coefficient of convective heat transfer is equal to $h_{1}=20 \mathrm{~W} /\left(\mathrm{m}^{2}{ }^{\circ} \mathrm{C}\right)$. Convective heat transfer between the air inside the collectors and the inner surface of collectors takes place with the coefficient $h_{2}=23 \mathrm{~W} /\left(\mathrm{m}^{2 \circ} \mathrm{C}\right)[9]$. Then air temperature inside the collectors will be computed using the formulas (2).

In the calculations of the mathematical model, change variants of the ground temperature are examined at different depths corresponding to changes in the ambient temperature $T_{V}$ for the range from $-5^{\circ} \mathrm{C}$ to $-25^{\circ} \mathrm{C}$. Figures 7 and 8 show graphs of the ground temperature change in the horizontal sections at different depths and the isotherms of the temperature field in the investigated area formed at outdoor air temperature $T_{V}=-15^{\circ} \mathrm{C}$. On the graphs of Figure 7 , it is clearly shown the influence of the proximity of collectors to the considered horizontal cross-section. Graphs II and III corresponding to depths $h=50 \mathrm{~cm}$ and $h=80 \mathrm{~cm}$ are distinguished by the great gradient, and one can see clearly on them the influence of the air temperature inside the collectors defined by (2).

Graph I, corresponding to the lower edge of asphalt concrete layer $(h=20$ $\mathrm{cm}$ ), is characterized by its smooth, and temperature difference between the air in the collector pipe of a forward and reverse flow is shown on it weaker. At the same time, the temperature difference of the air in the various collectors affects even up to the upper limit of the design scheme.

The same difference also affects the nature of the formation of the field of isotherms around underground collectors (Fig. 8). Density of isotherms is much higher in the domain adjacent to the collector tube of a feed-forward feed than in the domain corresponding to the collector pipe of a reverse feed. It was established as a result of a series of calculations that the value of $T_{V}=-5^{\circ} \mathrm{C}$ can be taken as the lower limit of the range of changes in the outdoor temperature, at which the conditions for the condensation of steam occur, in which the temperature in the collectors will be according to equation (2) $T_{k 1}=53.16^{\circ} \mathrm{C}$ and $T_{k 2}=34.14^{\circ} \mathrm{C}$, respectively.

In the work, methods for constructing a mathematical model of the temperature field formation in a multilayer road construction around an underground heat pipeline are given. Results of a natural experiment are used in the appointment of the boundary conditions in the mathematical model. Basic laws of the temperature distribution in the investigated domain are determined on the base of the mathematical model. 


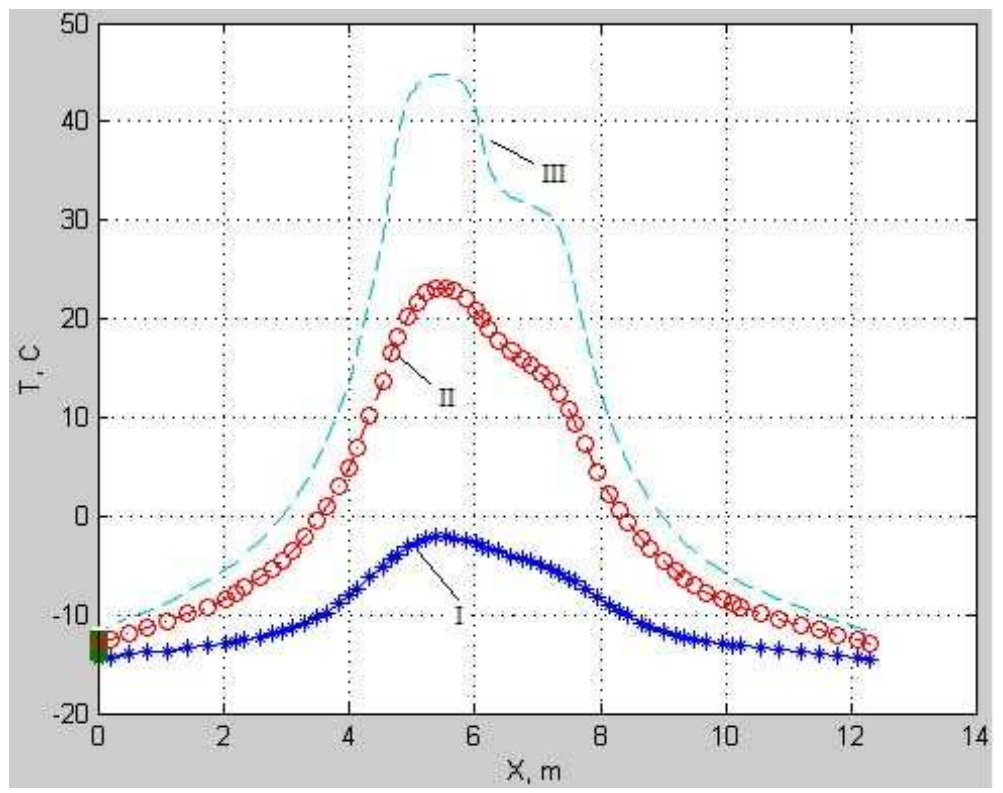

Figure 7: Graphs of temperature changes at depths $h=20 \mathrm{~cm}, h=50$ $\mathrm{cm}$ and $h=80 \mathrm{~cm}$ (graphs I, II, III) at values $T_{V}=-15^{\circ} \mathrm{C}, \quad T_{k 1}=$ $62.46^{\circ} \mathrm{C}$ and $T_{k 2}=41.04^{\circ} \mathrm{C}$

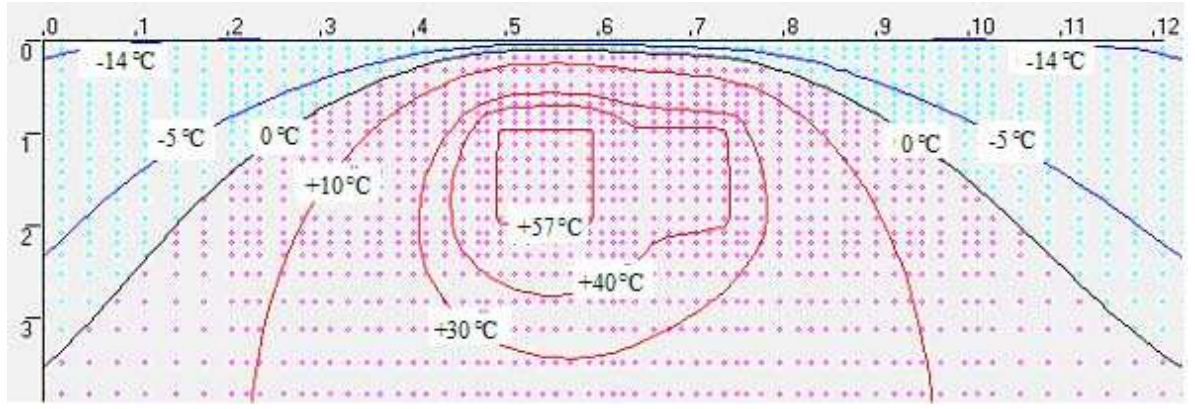

Figure 8: Isotherms of the temperature field at temperatures $T_{V}=$ $-15^{\circ} \mathrm{C}, T_{k 1}=62.46^{\circ} \mathrm{C}$ and $T_{k 2}=41.04^{\circ} \mathrm{C}$

\section{References}

[1] A.Ya. Tulaev, Regulation of Water-Heating Regime of Subgrade in Urban Environments, Visshaya Shkola, Moscow (1972). 
[2] Methodological Guidelines for the Design and Calculation of Pavement Roads and Streets of St. Petersburg on the Strength and Frost with Providing the Required Reliability, Lengiproinzhproekt, Transport Construction Management (1999).

[3] N.F. Fedorov, S.F. Veselov, Urban Underground Networks and Collectors, Textbook for High Schools, Stroyizdat, Moscow (1972).

[4] M.G. Goryachev, Experimental researches of hydrothermal regime of subgrade in the area of underground channel-free heating systems (M.G. Goraychev, A.N. Davidyak), Problems and development perspectives the Euro-Asian transport systems, In: Proceedings of International Scientific and Practical Conference, May 12-13, 2009, South Ural State University (2009), 197-200.

[5] M.G. Goryachev, Simulation of the temperature field on the channel-free heating systems in a case in ground medium (M.G. Goraychev, A.N. Y), Road Construction and Maintenance: Scientific Researches and their Realization, Moscow Automobile-Road institute (STU), A Collection of Scientific Works, Moscow (2008). 100-107.

[6] M.G. Goryachev, Prediction of temperature around the channel-free heat pipelines in the carrying case located in the subgrade of an automobile road (M.G. Goraychev, A.N. Davidyak), Status and Prospects of Transport. Making Roads Safe. A collection of scientific works. Vol.II. Publishing House of Perm State Technical University. Perm (2009). 72-78.

[7] Sh.M. Aytaliev, B.B. Teltaev, K. Aytbaev, Kh.S. Tursumbekova, On complex study of the temperature regime of urban road constructions above an underground heat pipeline, News of Higher Educational Institutions, Construction, No. 12 (2003), 66-70.

[8] V.P. Preobrazhenskiy, Thermo-Technical Measurements and Devices, Energy, Moscow (1978).

[9] L. Segerlind, Application of Finite Element Method, Mir, Moscow (1979).

[10] O. Zienkevich, Finite Element Method in Engineering, Mir, Moscow (1975). 